\title{
Integrated Risk Identification, Analysis, and Assessment: A Dynamic Household Economy Analysis Methodology and Example
}

\author{
Bob Alexander ${ }^{1 \%}$, Linda J. Cox ${ }^{2}$, and Junko Mochizuki ${ }^{2}$ \\ ${ }^{1}$ Rural Livelihood Risk Management Consulting, P.O. Box 1251, Honolulu, HI 96807, USA \\ ${ }^{2}$ Department of Natural Resource and Environmental Management, University of Hawai`i at Manoa, Honolulu, HI 96822, USA
}

\begin{abstract}
Many methodologies identify, analyze, and assess static risks to quantify potential disaster losses based on past and current events. Static methodologies will not, however, capture how climate change and adaptation are rapidly affecting the natural and social systems in many areas. Local and global changes such as those associated with development investments, livelihood pressures, political stability, and demographic trends are also affecting many areas, especially in emerging economies. Risk identification, analysis, and assessment methodologies must integrate all changes dynamically so that risk reduction and development decisions can be based on future needs. After a theoretical explanation of how to integrate dynamic changes, a static Household Economy Analysis (HEA) completed for a rapidly changing area of East Timor was altered using current trends to make the analysis more dynamic. Some inherent difficulties exist with a more dynamic approach and recommendations for overcoming them are presented. Research, government, and nongovernment personnel interested in integrated approaches to risk reduction and development decision-making in areas subject to rapid change will find the study useful.
\end{abstract}

Keywords Household Economy Analysis, integrated risk analysis, integrated risk assessment, vulnerability reduction

\section{Introduction}

The word "integrated" is used to describe many different approaches to disaster risk reduction (DRR) and climate change adaptation (CCA), causing confusion. Contemporary literature calls for integrating CCA and DRR (Kelman and Gaillard 2010; Mercer 2010) and for generally integrated approaches to development decision-making that incorporate changes in climate and disaster risks (White, Kates, and Burton 2001; Turner et al. 2003; Wisner et al. 2004; Birkmann 2006). The 2012 IPCC Special Report on Managing the Risks of Extreme Events and Disasters to Advance Climate Change Adaptation (IPCC 2012) has called for integration to better

\footnotetext{
* Corresponding author. E-mail: bfootbob@hotmail.com
}

understand the links between all factors that contribute to risk, especially the importance of characterizing dynamic uncertainty and complexity of development impacts, climate change, and vulnerability interventions (IPCC 2012). In emerging economies and other areas undergoing rapid change, factors such as development investments, livelihood pressures, political stability, and demographic trends are affecting natural and social systems too much to base decisions exclusively on past and current data.

The types of integration discussed in the literature include: bridging community risk reduction plans spatially with those of neighboring communities and upscaling with those of higher government levels (Daly et al. 2010); mainstreaming risk reduction into development plans (Mitchell 2003); including all internal subcommunity vulnerable groups and involved external stakeholders (Schmuck-Widmann 2001; Cronin et al. 2004; RTF-URR, UNISDR, and Kyoto University 2010; Mercer et al. 2010); considering all sectors and basic societal functions (Sundnes and Birnbaum 2003; Tran and Shaw 2007); utilizing biophysical and socioeconomic approaches in multidisciplinary studies (McEntire 2004; Larsen 2006; Kelman 2010); employing quantitative and qualitative methods (Wisner et al. 2004; Birkmann and Wisner 2006; Alexander, Bahnipati, and Rahman 2010); bridging across all risk factors (Louis 2007); and dynamically incorporating past, present, and future risks (Birkmann and Wisner 2006; Alexander, Bahnipati, and Rahman 2010). To address this confusion, Alexander and Mercer (2012) developed the framework in Figure 1, which incorporates all eight integration types to optimize for community risk identification, analysis, and assessment, while also allowing for evaluation and enhancement of the methodologies used to address integration.

Household Economy Analysis (HEA) is a food and livelihood insecurity assessment methodology developed in the 1990s to improve aid and agriculture decision-making. It is frequently used in countries in which people suffer from a lack of access to food and income (Frankenberger 1996; Boudreau 1998; Seaman 2000; Stephen and Downing 2001; 


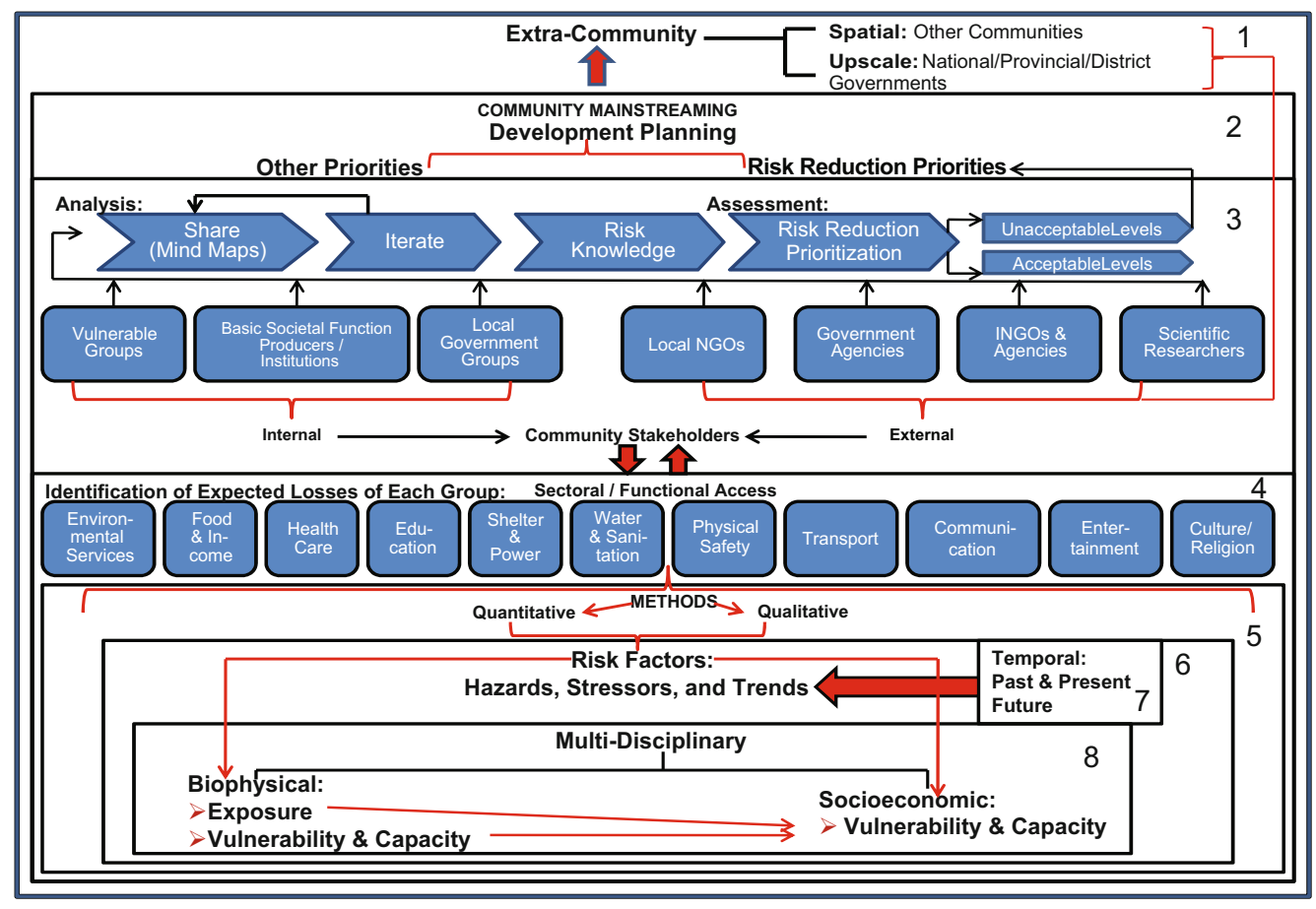

Figure 1. Framework for integration in community risk identification, analysis, and assessment

Source: Alexander and Mercer (2012). Reproduced by permission of the Asian Journal of Environment and Disaster Management.

Jaspars and Shoham 2002; FEG Consulting and Save the Children 2009). It quantifies how people within a community gain access to food and income in baseline years and predicts how much access will be affected by changes from a risk scenario in adverse years, using a common indicator. Information on baseline access to food and income, hazards and other factors affecting access to food and income, and coping strategies for obtaining food and income in adverse years is combined to estimate net food and cash income for the current year. This estimate is then compared to a survival threshold and a livelihood protection threshold to determine if survival or livelihood intervention is required.

Household Economy Analysis is a methodology that could incorporate all eight types of integration (see Table 1). Dynamic modifications would incorporate expected changes in the baseline and risk scenarios. A dynamic extension of HEA would determine if capacities are sufficient to ensure that food and income would be available to withstand everyday stresses and the occasional hazardous conditions that are expected (Wisner, Gaillard, and Kelman 2012).

Optimizing integration depends on location-specific assessment conditions, objectives, and constraints. HEA has been adapted to address some of them. The original HEA methodology remains appropriate for incorporating past and current trends to assess current year deficits in places with food and livelihood insecurity and people living below the poverty line (Okoth 2011). In areas such as Sri Lanka (Arumugam 2008, 2010) and the Congo (Guluma 2003) in which an ex post understanding of how paradigm changes, such as a major disaster event or cessation of conflict, have affected food and livelihood security, multiple HEAs can be conducted over time. RiskMap and its recent successor RiskMap2 are computer software programs developed for performing integrated spreadsheet analysis for Household Economy Analysis. They have allowed more rigor and robust analysis but currently lack some important elements required for dynamic prescriptive abilities (Rethman 2012). For such an ex ante dynamic understanding of the effects of changes and interventions, optimizing integration requires decisions regarding how to best analyze dynamic changes in the baseline and their outcome. Future scenario analysis is one candidate approach that has been recently combined with HEA to show potential future effects of livelihood activity, price, climate, and intervention changes on the baseline and outcome (FEWS-NET 2011; FSNAU-Somalia 2011; Diop and Faye 2012; FEG Consulting 2012a, 2012b; King 2012; Venton et al. 2012).

This article examines how the utilization of future scenarios can extend HEA to better integrate development planning and dynamically incorporate changing baseline conditions and risk factors. The methodology section examines the HEA process and proposes theoretical modifications to make the HEA framework more dynamic. Then the results of a static HEA and simulation results that include some dynamic assumptions are presented. These results are compared and some of the important implications are explored. Finally, suggestions for overcoming the limitations of applying a more dynamic methodology, as well as some concluding remarks, are presented. 
Table 1. Integration in Household Economy Analysis (HEA)

\begin{tabular}{|c|c|c|}
\hline Components & Met $^{\dagger}$ & Explanation ${ }^{\ddagger}$ \\
\hline \multicolumn{3}{|l|}{ (1) Extra-Community } \\
\hline - Spatial & $\sqrt{ }$ & $+:$ Grouped according to livelihood zone; changes affecting others incorporated into others' baseline \\
\hline - Upscaling & $\sqrt{ }$ & $+:$ Integrated spreadsheet provides for upscaling analysis \\
\hline \multirow[t]{2}{*}{ (2) Mainstreaming } & $?$ & $+:$ Identifies food and livelihood deficits \\
\hline & & - : No explicit incorporation into development plans \\
\hline \multicolumn{3}{|l|}{ (3) Stakeholders } \\
\hline - Internal & $\sqrt{ }$ & $+:$ Different subcommunity vulnerable groups analyzed through focus groups \\
\hline - External & $\sqrt{ }$ & $+:$ Key informants provide ongoing input \\
\hline \multicolumn{3}{|l|}{ (4) Sectors (Basic Societal Functions) } \\
\hline - Cross-functional consideration enabled & $\mathrm{X}$ & $\begin{array}{l}\text { N/A : Original objective is only understanding food and livelihoods (but can be modified to understand } \\
\text { cross-functional effects) }\end{array}$ \\
\hline (5) Methods & $\sqrt{ }$ & $\begin{array}{l}+ \text { : Participatory informed by external information; mix of quantitative and qualitative as appropriate } \\
\text { for objectives }\end{array}$ \\
\hline \multicolumn{3}{|l|}{ (6) Risk Factors } \\
\hline - All shocks and stressors considered & $\sqrt{ }$ & $\begin{array}{l}\text { +: Baseline incorporates stressors of normal years; risk scenario can incorporate effects of all likely } \\
\text { shocks in adverse years }\end{array}$ \\
\hline \multicolumn{3}{|l|}{ (7) Temporal } \\
\hline \multirow[t]{2}{*}{ - All trends considered } & $\mathrm{X}$ & $\begin{array}{l}\text { - : Baseline is based on conditions in past years and does not incorporate expected intervention, } \\
\text { development, climate, or other changes }\end{array}$ \\
\hline & & $\begin{array}{l}\text { - : Risk scenario and resulting expected losses and coping are based on past adverse years and do not } \\
\text { incorporate expected intervention, development, climate, or other changes }\end{array}$ \\
\hline (8) Multi-Disciplinary & $\sqrt{ }$ & $+:$ Baseline conditions and risk scenario can be appropriately informed by all \\
\hline
\end{tabular}

Note: ${ }^{\dagger} X=$ not achieved, $?=$ achieved to some extent, $\sqrt{ }=$ achieved; ${ }^{\ddagger}+=$ description of what was achieved, $-=$ description of what was not achieved.

\section{Household Economy Analysis Methodology: Static and Dynamic}

Although extensive information regarding the mechanics of the HEA methodology is available elsewhere (Boudreau 1998; FEG Consulting and Save the Children 2009), dynamic extension requires understanding the six steps described in Table 2. Steps 1 through 3 construct baseline sources and uses of food, non-food items, and income in normal years with no extreme hazardous events. In Step 1, Livelihood Zoning involves national and regional level key informants delineating which zones have the same general livelihood patterns so that each can be studied separately. In Step 2, Access Breakdown requires that key informants within a zone divide households into focus groups according to their wealth, household characteristics, gender, abilities, or other attributes that differentiate the levels of goods and services that people can access in normal and adverse times. In Step 3, Livelihood Strategies Analysis requires focus group representatives to reveal qualitative and quantitative information about types and percentages of the sources and uses of food, non-food items, and income in normal years. This sources and uses data is expressed as a percentage of minimum diet energy needs or of minimum income needed for survival. This enables comparison among the categories and across groups. If the total of all categories for any group is below the survival threshold, survival provisions can be explored.
In Steps 4 through 6, an adverse event year is compared to the baseline year to reveal group capacities, vulnerabilities, and threshold deficits. In Step 4, Problem Specification begins with key informants utilizing information regarding past disaster events and experiences to construct an adverse event scenario of the direct impacts for hazards affecting the community's production, market access, service provision, or other main drivers of sources and uses of food, non-food items, and income. The focus group representatives utilize this information to discuss their perceptions of how these impacts will cause further losses and/or be buffered by existing capacities. Quantitative and qualitative information are then compiled about these perceived effects on all types and percentages of the sources and uses of food, non-food items, and income discussed in the baseline analysis. In Step 5, Coping Capacity Analysis further reveals experience and knowledge of coping capacities and each group's expectation of how much coping will reduce the effects of losses on their food energy and income consumption. Finally, in Step 6, Projected Outcome involves calculating the projected minimum food energy needs or survival income that group members expect to access in an adverse year. These outcomes can then be compared to thresholds determined by the relief agencies for the food and income needed for survival and for ensuring that livelihood assets can be sustained. The resulting deficits indicate the expected required levels of survival or livelihood assistance. 
Table 2. Steps of Household Economy Analysis

\begin{tabular}{|c|c|c|c|c|}
\hline & Steps & General & Static & Dynamic \\
\hline \multirow[t]{3}{*}{$\begin{array}{l}\text { Baseline } \\
\text { Analysis }\end{array}$} & $\begin{array}{l}\text { Step 1: } \\
\text { Livelihood } \\
\text { Zoning }\end{array}$ & $\begin{array}{l}\text { - Define subnational/subregional zones with the } \\
\text { same general market infrastructure \& patterns of } \\
\text { access to goods \& services }\end{array}$ & $\begin{array}{l}\text { - Based on current \& } \\
\text { past data }\end{array}$ & $\begin{array}{l}\text { - Based on a Future Baseline Scenario } \\
\text { incorporating current/past data \& } \\
\text { investments/trends }\end{array}$ \\
\hline & $\begin{array}{l}\text { Step 2: Access } \\
\text { Breakdown }\end{array}$ & $\begin{array}{l}\text { - Subdivide households in a zone into focus groups } \\
\text { according to current access to goods \& services }\end{array}$ & $\begin{array}{l}\text { - Based on current \& } \\
\text { past information }\end{array}$ & $\begin{array}{l}\text { - Based on a Future Baseline Scenario } \\
\text { incorporating current/past data \& } \\
\text { investments/trends }\end{array}$ \\
\hline & $\begin{array}{l}\text { Step 3: } \\
\text { Livelihood } \\
\text { Strategies } \\
\text { Analysis }\end{array}$ & $\begin{array}{l}\text { - Elicit baseline information of sources \& uses of } \\
\text { food \& income from different focus groups } \\
\text { - Express combined data as baseline \% of minimum } \\
\text { energy or income needed for survival or sustaining } \\
\text { livelihood assets for each group }\end{array}$ & $\begin{array}{l}\text { - Based on current \& } \\
\text { past data }\end{array}$ & $\begin{array}{l}\text { - Based on current \& past data \& } \\
\text { expected changes from a Future } \\
\text { Baseline Scenario incorporating } \\
\text { investments/trends }\end{array}$ \\
\hline \multirow[t]{3}{*}{$\begin{array}{l}\text { Outcome } \\
\text { Analysis }\end{array}$} & $\begin{array}{l}\text { Step 4: Problem } \\
\text { Specification }\end{array}$ & $\begin{array}{l}\text { Define an adverse event scenario of direct hazard } \\
\text { impacts for households in an indicative adverse } \\
\text { event year on main drivers of sources \& uses of } \\
\text { food \& income } \\
\text { - Discuss indirect effects on all identified baseline } \\
\text { elements of sources and uses of food \& income } \\
\text { with focus groups (including buffering capacity) }\end{array}$ & 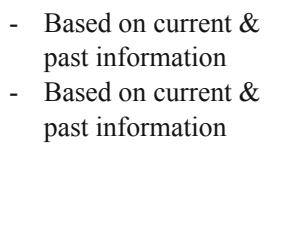 & $\begin{array}{l}\text { - Based on a Future Adverse Event } \\
\text { Scenario incorporating trends } \\
\text { - Based on current \& past data \& } \\
\text { expected changes from a Future } \\
\text { Baseline Scenario incorporating } \\
\text { investments/trends }\end{array}$ \\
\hline & $\begin{array}{l}\text { Step 5: Coping } \\
\text { Capacity } \\
\text { Analysis }\end{array}$ & $\begin{array}{l}\text { - Discuss effects of coping mechanisms to reduce } \\
\text { initial adverse effects with focus groups }\end{array}$ & $\begin{array}{l}\text { - Based on current \& } \\
\text { past information }\end{array}$ & $\begin{array}{l}\text { - Based on current \& past data \& } \\
\text { expected changes from Future Baseline } \\
\text { Scenario incorporating investments/ } \\
\text { trends }\end{array}$ \\
\hline & $\begin{array}{l}\text { Step 6: } \\
\text { Projected } \\
\text { Outcome }\end{array}$ & $\begin{array}{l}\text { - Subtract amounts likely saved through coping } \\
\text { from initial effects to reveal the projected deficit } \\
\text { from the baseline } \\
\text { - Express results for each group as projected \% } \\
\text { deficit of minimum energy or income needed for } \\
\text { survival or sustaining livelihood assets for each } \\
\text { group } \\
\text { - Utilize deficit \%s to predict levels of survival } \\
\text { and/or livelihood assistance to be needed }\end{array}$ & $\begin{array}{l}\text { Express results for } \\
\text { each group as static } \\
\text { projected \% deficit } \\
\text { relative to thresholds } \\
\text { - } \quad \text { Utilize deficit } \% \text { s to } \\
\text { predict levels of } \\
\text { reactive assistance to } \\
\text { be needed }\end{array}$ & $\begin{array}{l}\text { - Express results for each group as } \\
\text { dynamic projected \% deficit relative to } \\
\text { thresholds } \\
\text { - Utilize deficit \%s to predict: levels of } \\
\text { deficits to be addressed through } \\
\text { proactive adaptation and prevention } \\
\text { measures; potential effects of invest- } \\
\text { ments on deficits }\end{array}$ \\
\hline
\end{tabular}

Because of its collaborative ability to predict expected deficits, HEA has been used by programs whose focus is on post-event survival and livelihood assistance (FEG Consulting and Save the Children 2009). The past, however, is now less indicative of future expectations in places where hazard, climate, related adaptation, investment, interventions, and other changes are rapidly altering capacities and vulnerabilities. This suggests that making the methodology more dynamic by incorporating expectations of future changes would allow HEA to be used for planning and optimizing proactive adaptation and prevention measures for DRR, CCA, and development programs.

The first step in addressing the limitation of using past and current data is the formulation of Future Baseline Scenarios and Future Adverse Event Scenarios. These are predictions for a certain time period based on discussions with external stakeholders such as government agencies, international organizations, and scientists and internal stakeholders such as local leaders, local NGOs in the area, local providers of goods and services, and community vulnerable subgroup members. The Future Baseline Scenario is a summary of current and expected changes in basic functions that affect household access to goods and services. Such changes may include investments and trends related to climate, environmental amenities, markets, demography, land use, food production and availability, health care, education, housing, power, water supply, sanitation, public safety, transportation, communications, recreation, and religious and cultural activities. While more opinions are generally better, the result must be synthesized into a format that can be understood and used at the community level such as a visual future land use map and simple categorized descriptions of main expected changes. Likewise, the Future Adverse Event Scenario is a synthesized and usable summary of how these Future Scenario changes will affect household and livelihood vulnerabilities and adaptive and buffering capacities in the community and how these expected changes will interact with expected changes in hazards and other risk factors. The process must ensure that the perceptions of different stakeholders are valued. The scenario must be neither too controversial nor too inaccurate. As any resulting scenarios that can be effectively used and are indicatively better than using only past and present data are desirable, perceptions of accuracy must be balanced with acceptability. 
Dynamic changes in the HEA process depend on how these scenarios are used. As shown in Table 2, Future Baseline Analysis begins with adding the Future Baseline Scenario to Step 1 to allow any expected changes in demography, land use, and market infrastructure to help predict the zones to be used in planning. In Step 2, Access Breakdown is based on the current community groups' expected changes in normal and adverse years due to investments and various trends. When working in the community, an understanding of the current baseline for sources and uses of food, non-food items, and income must be achieved with focus groups before any discussion can be effective. After perceptions of current baseline sources and uses are revealed in the Livelihood Strategy Analysis, the Future Baseline Scenario can be explained so that perceived impacts can be elicited to compile the expected future baseline.

Using this future baseline for comparison, Future Outcome Analysis bridges perceptions of external researchers and internal observers to create a Future Adverse Event Scenario based on expected changes in hazards, vulnerabilities, and capacities in the community. In Step 4, after focus group discussions of vulnerabilities and capacities to withstand past and present hazards, Problem Specification utilizes discussion of the Future Adverse Event Scenario to develop an understanding of the expected changes for adverse year disaster events. This will include expected effects of climate change and of related climate change adaptation measures. A discussion of their expected indirect effects and those of the Future Scenario on their vulnerabilities and capacities to prevent losses then follows. Participatory exercises reveal the expected future losses of sources and uses of food, non-food items, and income.

In Step 5, Coping Capacity Analysis considers the expected effects from the Future Scenario on poverty conditions and adverse year production, sale, consumption, and acquisition on losses of food energy consumed or income earned. In Step 6 , the Projected Outcome percentages are compared to the threshold scenarios. Expected future deficits between the future baseline and these thresholds can be used to plan for post-event survival and livelihood maintenance to reduce future losses. The following section describes simulation of the results of a dynamic HEA using a case study from Timor Leste. This case study illustrates how a dynamic HEA could determine the potential effects of agricultural investments and other changes on future deficits so that planning as well as adaptation, prevention, and assistance could be modified accordingly.

\section{Static Case Study and Dynamic Simulation}

In 2004, as part of an integrated project in Venilale subdistrict of Timor Leste, project beneficiaries, local extension agents, national ministry employees, and international agency officers sought information regarding the potential effects of new seeds, crops, and agricultural methods that were being considered for implementation. Concerns were also expressed about the effects of flooding, droughts, rat infestations, and other hazards on the area. A simple, static Household Economy Analysis was conducted with project beneficiaries in Venilale who were part of a workshop aimed at improving district-level and farm-level agricultural decision-making (Alexander 2004; Alexander, Bahnipati, and Rahman 2010).

Venilale is located in the district of Baucau in the interior of the Seical watershed in the northeastern part of Timor Leste. The profile of relevant socio-demographic characteristics for the area for the purposes of the methodology is found in Table 3. This case study serves as an example of how the methodology can be integrated to include effects of development initiatives, climate change, and hazard events as part of a risk scenario of a 40 percent loss in crops from the aforementioned hazards that represent an indicative bad year. The introduction of a dynamic adverse event scenario demonstrates how HEA can be extended in any location to better dynamically integrate the risk factors associated with climate change and examine the effect of a proposed investment in agricultural decision-making.

Computation of the energy deficiencies for different groups was completed by the external facilitator based on the input of and direction from community members. Computations requiring information from community members and used by community members in collaborative decision-making is an inherent limitation of quantitative methodologies. Maximizing community engagement through increased capacity within the community to conduct the arithmetic calculations and to create and analyze spreadsheets of resulting data should improve credence of the results and the community's overall participation in decision-making.

In Venilale, the livelihood zoning, market analysis, and vulnerability groupings were completed with key informants according to HEA guidelines utilizing the assumptions listed in Table 3. Focus groups then used the participatory method of proportional piling to provide data for their sources of food, uses of food, sources of non-food income, and expenditures analysis. From these data, the baseline total income as a percentage of the 2100 kilocalories minimum daily energy needs was calculated as the sum of food income in kilocalories and non-food income converted to kilocalories. As shown in Figure 2, although survival and livelihood protection thresholds were not determined for this study, baseline analysis results of 191 percent and 171 percent of minimum energy needs for the high and average access groups seemed relatively high while the low access group result, at 114 percent, was likely very near the livelihood protection threshold in normal years.

For the outcome analysis, key informants and focus group participants determined the potential effects of hazard or disaster event damages on this baseline. They agreed on an adverse event scenario of 40 percent of crops being destroyed from a combination of hazards in a typical 1-in-10 year "bad 
Table 3. Summary of assumptions in the 2004 Household Economy Analysis

\begin{tabular}{|c|c|}
\hline Item & Explanation \\
\hline \# of people per household & 6 (from key informants in 2004) \\
\hline Survival & $\begin{array}{l}2100 \mathrm{kcals} / \text { day} / \text { person } \times \# \text { of people in house } \times 365 \text { days } / \text { year }=\text { minimum } \mathrm{kcals} / \text { household } / \text { year }(\text { WFP } / \mathrm{UNHCR} \\
1997)\end{array}$ \\
\hline Thresholds & Survival $=100 \% ;$ Livelihood Protection $=110 \%$ \\
\hline Land Allocation (ha) & $\begin{array}{l}\text { Low }=0 \text { rice, } 1 / 2 \text { corn, } 1 / 2 \text { vegetables/legumes/tubers; Medium }=1 \text { rice, } 1 \text { corn, } 1 / 2 \text { vegetables/legumes/tubers; } \\
\text { High }=3 \text { rice, } 1 \text { corn, } 1 \text { vegetables/legumes/tubers (based on figures given by key informants) }\end{array}$ \\
\hline Cash Income & Low $=$ USD 100; Medium $=$ USD 500; High $=$ USD 1000 (based on mid-ranges of figures given by key informants) \\
\hline Initial Adverse Event Scenario & initial $40 \%$ loss of crops \\
\hline Coping & $\%$ s of pre-coping consumption losses from adverse event: $8 \%$ low; $23 \%$ medium; $33.3 \%$ high \\
\hline Conversion factor for USD to kcals & USD $1=8 \mathrm{~kg}$ rice paddy yield $=4.06 \mathrm{~kg}$ corn yield (based on 2004 prices, including milling and storage losses) \\
\hline
\end{tabular}

year." Due to different indirect effects across groups, discussions of the deficit effects resulted in a 50 percent decrease in consumption for the low group, 42 percent for the medium group, and 45 percent for the high group. Consideration was then given to the expected effects of coping such as reducing savings, borrowing, receiving remittances, selling assets, making and selling items, growing and selling short-duration crops, and consuming otherwise inferior foods. Total income as a percentage of minimum daily energy needs was calculated again for the adverse year with and without the effects of coping. The high group's initial baseline level and more effective coping mechanisms resulted in a level of spending equal to 134 percent of minimum energy needs that, while reduced, was well above any livelihood protection threshold. The medium group, at 116 percent, might have required livelihood assistance. The low group, struggling with livelihood protection even in normal times and dropping to 62 percent of its minimum energy needs in adverse times, would have needed significant survival assistance.
These results reflect static vulnerabilities as assessed in 2004. To analyze the net results of any endogenous interventions, other endogenous dynamic changes, or exogenous changes, a dynamic HEA methodology is required. If a dynamic HEA had been conducted in 2004, future scenarios would have been constructed collaboratively by internal and external stakeholders to determine the expected future changes in the baseline and a future adverse event. As this was not done as part of the original study, the lead author returned to the study area in 2011 to simulate this by utilizing information gained from key informants and related research reports about relevant trends affecting livelihood zones, access groups, and baseline sources and uses of food and income in the previous seven years. Information was also obtained regarding expected changes over the next three years to simulate a Future Baseline Scenario and Future Adverse Event Scenario. These inputs were used in place of baseline and outcome analysis with the participatory focus groups as required by the methodology, and the types of results that

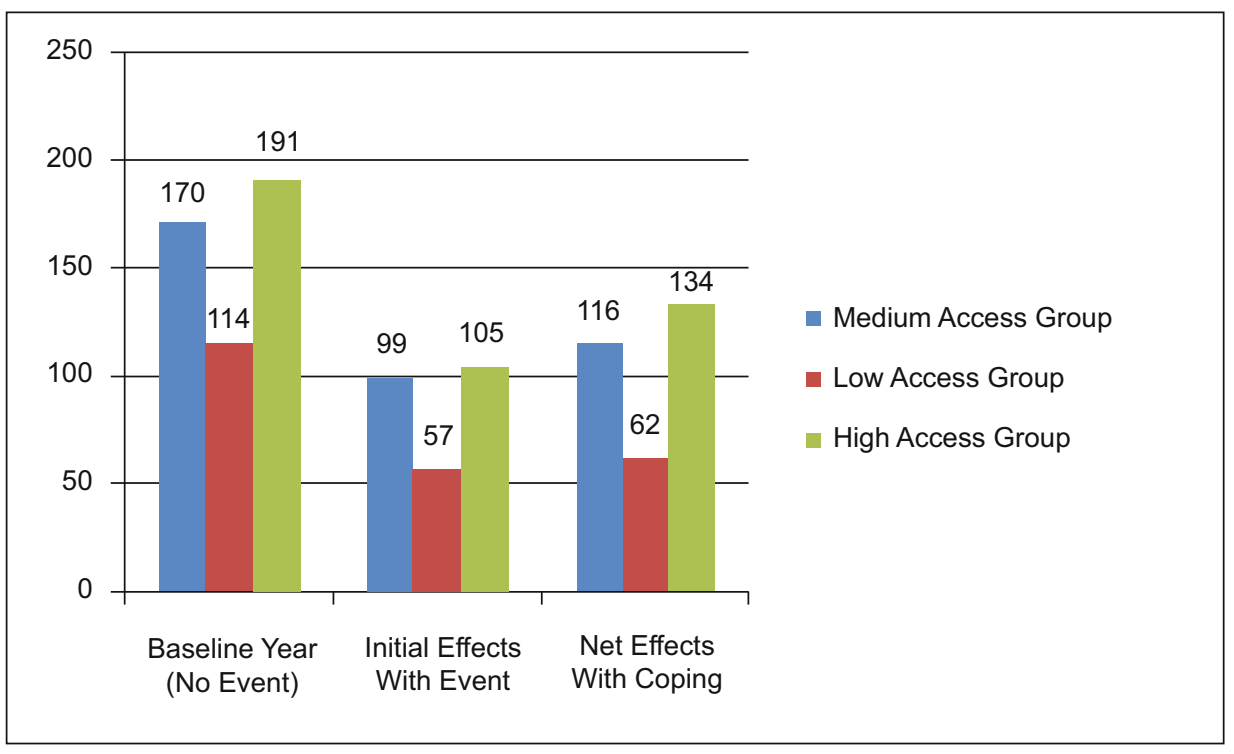

Figure 2. Initial Household Economy Analysis (HEA) percentage results 
might have been obtained were simulated using a spreadsheet algorithm. The results are meant to illustrate the usefulness of conclusions that might be drawn from a dynamic HEA methodology.

If the dynamic HEA methodology had been employed, the stakeholders would have been involved in discussing trends to create the scenarios. Instead, for simulation of potential results of that process, a number of important changes taking place in Venilale were used by the lead author in consultation with representatives of agencies working in the area to make indicative assumptions for use in the scenarios. Changes from the static assumptions and the rationale for them in the dynamic baseline analysis are shown in Table 4. Despite significant expected increases in population (Molyneux et al. 2012), the livelihood zones and access breakdowns are assumed for simplicity to remain the same. For the Livelihood Strategies Analysis this population increase could be important. Each family's size was arbitrarily assumed to increase from six to eight although results are subject to sensitivity analysis with bigger or smaller increases for different groups. To feed this larger population, productivity of the staple crops of corn and rice are increasing. The 2010 World Bank report on agricultural productivity in Timor Leste described key improvements for rice and corn as GiZ's Integrated Crop Management (ICM) methods for rice and the new varieties and storage methods for corn introduced by a program of Timor Leste's Ministry of Agriculture and Fisheries called Seeds of Life (World Bank 2010). Yield per hectare is expected to increase by more than 100 percent for rice using ICM methods and more than 40 percent for corn with the new sele variety. For simplicity, yield increases are assumed to affect all access groups uniformly though yield increases for those with more capital and input access could be better.

In a complete dynamic analysis, expected changes in costs of production over time should be included. For this indicative simulation that focuses on changes in yields, adverse events, and population, the differences in costs of the new corn variety and rice methods are considered negligible since increased fertilizer and other inputs are not considered significant factors in yield functions. Generally from the farmer's viewpoint, input costs should be decreasing as more, better inputs are free from the government and about 50 percent less seed and fertilizer are needed per hectare for planting rice in ICM rows. No changes are expected in milling losses for rice or shelling losses for corn. Although corn storage losses from moisture and weevils are expected to increase with the sele variety, an improved corn storage method was introduced by Seeds of Life. This method can eliminate storage losses for both corn varieties entirely. Informants expected no significant increase in the percentage of rice or corn sold or purchased since the expected production

Table 4. Steps and assumptions of the dynamic baseline analysis

\begin{tabular}{|c|c|c|}
\hline Item & Expected Change & Rationale \\
\hline \multicolumn{3}{|c|}{ Using Future Baseline Scenario Assumptions: } \\
\hline Step 1: Livelihood Zones & No change & Assume no significant change to production and marketing by zone \\
\hline $\begin{array}{l}\text { Step 2: Access Group } \\
\text { Breakdown }\end{array}$ & No change & $\begin{array}{l}\text { Some within groups changing, number of fields allocated to rice or corn is } \\
\text { changing for some, standard of living for some increasing with higher } \\
\text { expenditures; per Molyneux et al. (2012), population in each livelihood zone } \\
\text { is increasing, so assume that household size increases from } 6 \text { to 8; assume } \\
\text { that the combination of agricultural improvements and population growth } \\
\text { results in composition of the access groups not changing significantly }\end{array}$ \\
\hline
\end{tabular}

Step 3: Livelihood Strategies Analysis

Consumption Rice \& corn consumption increases as a \% of increased production

Normal year production $\quad$ Corn up $40 \%$; Rice up $100 \%$

Post-harvest corn losses

Post-harvest rice losses

Thresholds
Storage losses (from the moisture \& weevils during storage): $20 \%$ traditional \& 50\% new sele variety;

Shelling losses (from removal of the husk and cob from the kernels): constant at $0.8187 \mathrm{~kg}$ kernels / $1 \mathrm{~kg}$ yield rate;

Milling losses remain constant at $50 \%$

No change
All other consumption constant (no consumption function; no substitution; consume all grown up to 4 tonnes with no increases in sales or purchases; no price forecasting possible)

Productivity increases are based on expected effects of the new corn variety $\&$ new rice ICM tactics

Storage losses: the new variety is more vulnerable

Shelling losses: no change from new storage methods or new varieties

No change in post-harvest losses for rice (the new storage methods are not used for rice)

Survival threshold constant;

Other than rice and corn yields, livelihoods are not changing enough to change the livelihood protection threshold from the originally $110 \%$ of energy needs 
Table 5. Steps and assumptions of the dynamic outcome analysis

Utilizing Future Adverse Event Scenario and Future Baseline Scenario Assumptions:

Step 4: Problem Specification

Climate change \& other CEP Increase for each group by $5 \%$ (high from

effects on consumption loss $45 \%$ to $50 \%$, medium from $42 \%$ to $47 \%$, low from $50 \%$ to $55 \%$ )

Storage loss reduction

$20 \%$ traditional and $50 \%$ sele corn variety storage losses eliminated
Increased severity of extreme events and negligible changes in normal years in Timor Leste

Seeds of Life recommended storage methods eliminate corn vulnerability to moisture and weevils; no change for rice

Step 5: Coping Capacity Analysis

Coping Constant $\%$ of consumption losses $(8 \%$ for No change in coping abilities

low, $23 \%$ for medium, $33.3 \%$ for high)

Step 6: Projected Outcome

Projected Outcome No change in procedure

Thresholds assumed constant

threshold for increased sales of yields of four tonnes per hectare would not be reached until after the cutoff date for analysis. For a more thorough analysis, consumption functions with the elasticity of the percentage purchased, sold, and substituted for consumption with the expected percentage changes in production and expected effects of forecast price changes might be considered. Kilocalories needed for survival varies with people's sizes, metabolisms, and ages but average energy needs can be assumed to remain constant. As there are also no significant expected changes in types of livelihoods, the thresholds are assumed constant.

The major change in assumptions for the dynamic adverse event scenario, as shown in Table 5, is an assumption attributed to the effects of climate change and other creeping environmental problems (CEP). Although changes in productivity from climate and related changes in Timor Leste are expected to be negligible in normal years (Molyneux et al. 2012), extreme events are expected to have more severe impacts (Kirono 2010). Precise projections of the meteorological, production, or consumption effects on the different groups would improve dynamic predictive ability. Since they are not yet available, this simulation assumed an initial value subject to a 5 percent increase in pre-coping consumption losses for each group. A more thorough analysis might also consider effects of expected changes from adaptation, including preparedness for coping and buffering of direct and indirect losses. Buffering through elimination of corn storage losses should significantly improve the amount of food available in the "hungry months" of adverse years. Although improved production could positively affect coping through savings and population increases and CEP could negatively affect mechanisms such as access to inferior foods or quick crop planting, coping as a percentage of initial losses is assumed constant.

Incorporating these assumptions into the spreadsheet simulation algorithm produced the results in Table 6. The most significant simulation result is that the increases in agricultural productivity provide very little help for the most vulnerable group in normal and adverse years because most of their food and income comes from sources that do not benefit from these improvements. If yields improve enough to increase the amount sold and decrease prices or to increase the need for labor on the agricultural fields of the high and medium access groups, this low access group might eventually benefit. Even without considering the effects of climate and population change, the low group would remain in need of survival assistance in adverse years unless new livelihood innovations benefit them. Climate change effects would eliminate all their marginal gains and population change would exacerbate their vulnerability to being unable to meet survival and livelihood thresholds.

The group with the most access to resources would benefit from better yields in normal and adverse years despite climate and population change. The gains for the average group may

Table 6. Selected simulation results

\begin{tabular}{|c|c|c|c|c|c|c|}
\hline$\%$ of Survival Kcals & Original & $\begin{array}{c}\text { With ICM Rice \& } \\
\text { New Corn Seed }\end{array}$ & $\begin{array}{c}\text { With ICM Rice \& } \\
\text { New Corn Seed \& } \\
\text { Storage }\end{array}$ & $\begin{array}{c}\text { With All \& Climate } \\
\text { Change }\end{array}$ & $\begin{array}{c}\text { With All \& Pop. } \\
\text { Change (No Climate } \\
\text { Change) }\end{array}$ & $\begin{array}{c}\text { With All \& Pop. } \\
\text { Change \& } \\
\text { Climate Change }\end{array}$ \\
\hline High Baseline & 191 & 328 & 344 & 344 & 258 & 258 \\
\hline High Outcome & 134 & 229 & 241 & 230 & 181 & 172 \\
\hline Medium Baseline & 170 & 238 & 258 & 258 & 193 & 193 \\
\hline Medium Outcome & 116 & 161 & 174 & 164 & 131 & 123 \\
\hline Low Baseline & 114 & 118 & 126 & 126 & 95 & 95 \\
\hline Low Outcome & 62 & 64 & 68 & 62 & 51 & 47 \\
\hline
\end{tabular}


be just enough to push them above the livelihood maintenance threshold in adverse years. Sensitivity analysis that reduces productivity gain and increases population growth assumptions can eliminate these gains entirely. The corresponding results show that the low access group will face severe challenges to their survival and resilience, findings that would not be anticipated based on the static HEA results. These findings support the claim by Molyneux et al. (2012) that population change will negate gains of agricultural productivity in Timor Leste and further show that the absence of price, labor, or beneficial development effects will result in further weakening the survival and resilience of those with least access to land and other resources. This simulation shows the type of implications that such a dynamic analysis could reveal.

\section{Discussion and Recommendations}

The preceding case study is only intended to be indicative of how the proposed dynamic HEA methodology might be useful. In doing so, it reveals significant differences between the results of a static and a dynamic analysis in an area that exemplifies the rapidity of change in many areas. Like in Venilale, baseline and risk factor conditions are changing rapidly elsewhere due to effects of such factors as new investment, land use, and livelihood practices; demographic change; alterations of the environmental landscape; variability of climate and extreme events; and adaptation to them. In such areas of rapid change, static risk identification, analysis, and assessment will not help people to anticipate and adapt to the risks that they are likely to face.

The required dynamic analysis is more complex in terms of input and analysis required. One potential problem relates to the need for many assumptions regarding changes and how those changes will influence other factors. A limitation of the simulation in this study was that these assumptions and the resulting scenarios were not collaboratively developed by the stakeholders in the effects of change in the area as proposed in the methodology. For this simulation, potential changes in production costs; in purchase, sale, and substitution with increased production; in livelihood zones and access groups; and in effects on adaptation, buffering, and coping were neglected for simplicity. Figures for expected population growth and impacts on extreme events from climate change and creeping environmental problems were assigned arbitrarily based on their expected direction. Accurate local data regarding meteorological, production, and consumption effects of climate change in normal and adverse years remain unavailable, but emphasis should be placed on creating flexible scenarios that provide indicative information subject to change. Useful scenarios can be developed through bridging perceptions of biophysical and socioeconomic researchers that focus on the potential natural and social systems effects and the perceptions of key informants and focus group representatives about how these may translate into specific direct and indirect impacts on food and income in the community.
More indicative results will be obtained in future analyses if disciplines, methods, and stakeholder integration produces more accurate assumptions about expected changes.

Another potential problem with risk assessments in areas of rapid change is that temptations arise to consider qualitative information from at-risk community discussions as less useful than externally generated model-driven quantitative information. Such external models can provide useful indications of the sources and amounts of change and can also be based on subjective assumptions that do reflect the local current context. External models cannot incorporate institutional breakdown, cascading disaster effects, and the resulting losses as effectively as focus groups. Focus group discussion results that are informed by scenarios based on internally and externally generated models of likely changes and that are triangulated with focus group discussions and external analysis can best lead to useful information for decisionmaking. In order to inform these discussions, scenarios need to creatively incorporate what changes are known, along with the complexity and uncertainty of unknown changes in ways that are understandable and usable for triggering focus group discussion. Differing perceptions should be valued in a manner that balances acceptability and accuracy. A dynamic HEA should be tailored so that all such possible sources of relevant information are synthesized for optimal risk-based development decision-making.

Returning to Venilale seven years after the original study, which provided baseline data for this study, was done only to simulate the scenarios that would have been a part of the original analysis in a true dynamic HEA. This is not meant to indicate that dynamic studies that incorporate scenarios are stand-alone assessments. Longitudinally comparing results over time and modifying scenarios to more accurately reflect expectations of changes should be part of a continuous dynamic assessment process. Part of this continuous assessment process should involve capacity building to improve the skills of internal stakeholders in conducting the analysis. As mentioned previously, a dynamic HEA should aim to minimize the disruption of the collaboration between internal community members and external facilitators that can be inherent in studies utilizing some quantitative computations. One way of minimizing this disruption is to train representatives of the community in the basic arithmetic and spreadsheet analysis that will enable them to eliminate disempowering division of roles. Continuous assessment could then involve determination of expected needs that is co-facilitated by internal and external stakeholders in the decisions that will result regarding planned investments and adaptation.

One significant advantage of the HEA approach to stakeholder integration is its intrinsic focus on differentiating across vulnerable groups within communities. Recent criticisms of food and livelihood insecurity assessments that have failed to address differences in groups emphasize the need for focus group analysis to understand long-term socio-political marginalization processes. These dynamics result in significant differences in how different groups are affected by 
Table 7. Assessment evaluation table template

\begin{tabular}{ll}
\hline Components & Met $(\mathbf{Y} / \mathbf{N})$ \\
\hline Extra-Community & \\
- Spatial & \\
- Upscaling & \\
\hline Mainstreaming & \\
\hline Stakeholder & \\
- Internal & External
\end{tabular}

Sectors (Basic Societal Functions)

Methods

Risk Factors

Dynamic

Disciplines

food and livelihood insecurity triggers (Collinson et al. 2002; Majid and McDowell 2012). The simulation in this study did not explicitly incorporate long-term socioeconomic changes in baseline or coping access among different groups and recommends considering such changes in future studies.

Finally, optimizing integration depends on locationspecific conditions, objectives, and constraints. While most factors are important to consider theoretically, resource availability for the assessment may limit the extent of integration that is optimal. Optimization depends on the perceived importance of the different types of integration on the projected deficits and the prescribed investments and interventions given the resources available for the study. A practical recommendation for implementing integration optimization is for all agencies proposing an HEA or other risk identification, analysis, or assessment to include a one-page evaluation in the inception report describing how much of each type of integration is to be included in the study. Like the template evaluation table in Table 7, this evaluation should include justification for including or not including each type and explaining the methodology that will be used to address the local conditions, objectives, and constraints.

\section{Conclusions}

The many types of integration in risk identification, analysis, and assessment methodologies lead to confusion and to a silo approach to providing information for decision-making. Despite improvements in bridging some aspects of disaster resilience work, obstructions remain due to the separation of responsibilities between NGOs doing response and risk reduction work and governments doing development and environmental planning work; perceived budget conflicts among agencies responsible for climate change adaptation, disaster risk reduction, and development work; and lingering misconceptions about climate change work being focused on the environment and the future and disaster work being focused on response and the past. Following the types of integration in Alexander and Mercer (2012), this article demonstrates ways to improve the use of integration in a representative risk identification, analysis, and assessment methodology so that its results are more useful for risk reduction and development decision-making.

HEA was identified as an interesting methodology for extension because it already addressed most aspects of integration and was found lacking in aspects deemed important in recent literature. In locations undergoing rapid environment and development-induced changes, dynamically incorporating changing risk factors to better enable risk reduction and multi-sector development decision-making is needed. The dynamic HEA extension improved the methodology by indicating predicted deficits of food and income based on changes that are expected to affect the ability of household groups to access them in normal and adverse years. In doing so, it enables better integration into development decisionmaking because agencies can consider the potential effects of proposed investments and other proposed changes on future deficits. Such dynamic analysis will help ensure that challenges such as those faced by disadvantaged populations in the analysis can be better anticipated and addressed.

A dynamic HEA should also optimize stakeholder integration to co-create risk knowledge for risk-based development decision-making as described in Alexander and Mercer (2012). It can help to integrate analysis of livelihoods and markets with analysis of other sectors and functions by linking the analysis to models for water, health care, and other sectors to show cross-sector effects of investments and interventions. Further research is recommended to determine how to locally optimize integration. For this, comparison of the insights from this article with those in Alexander and Mercer (2012) and other relevant recent studies of integration 
is recommended. Further research is also recommended regarding how to locally implement a dynamically integrated HEA and to generate the underlying future scenarios. Additionally, the foregoing evaluation and extension approach should be considered for optimizing integration in other food and livelihood insecurity assessment and other risk identification, analysis, and assessment methodologies.

\section{References}

Alexander, B. 2004. Technological Change, Product Change, and Risks. Proceedings of the Workshop Training for Improving Agricultural Decision-Making in Timor Leste. July 26-30 and August 3-4, 2004. Dili, Timor Leste: Government of Timor Leste Ministry of Agriculture, Forestry, and Fisheries.

Alexander, B., C. S. Bahnipati, and M. A. Rahman. 2010. Practical Disaster Risk Reduction and Climate Change Adaptation Assessment Methods. In Disaster Risk Reduction and Climate Change Adaptation: Case Studies from South and Southeast Asia, UNU-EHS Source 14/2010, edited by N. Setiadi, J. Birkmann, and P. Buckle, 62-76. Bonn: UNU-EHS Source Publication.

Alexander, B., and J. Mercer. 2012. Eight Components of Integrated Community Based Risk Reduction: A Risk Identification Application in the Maldives. Asian Journal of Environment and Disaster Management (4) 1: 533-548.

Arumugam, V. 2008. Sri Lanka: Livelihood Assistance to the Poorest Tsunami Affected Households in Sri Lanka Pre-Intervention Individual Household Economy Survey Results. Save the Children Sri Lanka. Final Report. 22 September 2008.

Arumugam, V. 2010. Sri Lanka: Livelihood Assistance to the Poorest Tsunami Affected Households in Sri Lanka Post-Intervention Individual Household Economy Survey Results. Save the Children Sri Lanka. Final Report. 29 May 2010.

Birkmann, J., ed. 2006. Measuring Vulnerability to Natural Hazard: Towards Disaster Resilient Societies. Tokyo: UNU Press.

Birkmann, J., and B. Wisner. 2006. Measuring the Un-Measurable, The Challenge of Vulnerability. Bonn,:UNU-EHS.

Boudreau, T. 1998. The Food Economy Approach: A Framework for Understanding Rural Livelihoods. Relief and Rehabilitation Network Paper \#26. London: Overseas Development Institute.

Collinson, S., M. Bhatia, M. Evans, R. Fanthorpe, J. Goodhand, and S. Jackson. 2002. Politically Informed Humanitarian Programming: Using a Political Economy Approach. Humanitarian Practice Network, Network Paper. London, Overseas Development Institute.

Cronin, S. J., D. R. Gaylord, D. Charley, B. V. Alloway, S. Wallez, and J. W. Esau. 2004. Participatory Methods of Incorporating Scientific with Traditional Knowledge for Volcanic Hazard Management on Ambae Island, Vanuatu. Bulletin of Volcanology 66 (7): 652-668.

Daly, M., P. Namouta, F. Nelson, and J. Kohlhase. 2010. Reducing the Climate Vulnerability of Coastal Communities in Samoa. Journal of International Development 22 (2): 265-281.

Diop, A., and O. Faye. 2012. Senegal Scenario Analysis 2011-2012: Two Rural Livelihood Zones Assessed Using the Household Economy Approach (HEA). London: Save the Children UK.

FEG Consulting (The Food Economy Group), and Save the Children. 2009. The Practitioners' Guide to the Household Economy Approach. Johannesburg: Regional Hunger and Vulnerability Program.

FEG Consulting (The Food Economy Group). 2012a. Social Protection / Poverty Case Study Singida, Tanzania. http://www.feg-consulting. $\mathrm{com} /$ core issues/social/case-study-singida-tanzania-1/.

FEG Consulting (The Food Economy Group). 2012b. HWEA Information Sheet - Growth Lars: Household Water Economy Assessment (HWEA). http://www.feg-consulting.com/spotlight/INFORMATION SHEET_HWEA_rfs.pdf.
FEWS-NET (Famine Early Warning Systems Network). 2011. Executive Brief Niger December 9, 2011 - Household Economy Approach (HEA) Outcome Analysis: Ouallam Cropping/Herding with High Work Outmigration Livelihood Zone. http://www.fews.net/docs/ Publications/Niger Ouallam 201112 en.pdf.

Frankenberger, T. 1996. Measuring Household Livelihood Security: An Approach for Reducing Absolute Poverty. Food Forum 24, Washington, DC: Food Aid Management.

FSNAU-Somalia. 2011. Livelihood Baseline Analysis Addun Pastoral. July 4, 2011, Technical Series Report No VI. 38. Food Security and Nutrition Analysis Unit - Somalia.

Guluma, Y. 2003. Household Economy Analysis of the Rural Population of the Plateaux Zone, Masisi, North Kivu, Democratic Republic of Congo. Save the Children UK DRC Programme. http://www.kongokinshasa.de/dokumente/ngo/sc-bwitorep-jan03.pdf.

IPCC (Intergovernmental Panel on Climate Change). 2012. Managing the Risks of Extreme Events and Disasters to Advance Climate Change Adaptation. Cambridge: Cambridge University Press.

Jaspars, S., and J. Shoham. 2002. A Critical Review of Approaches to Assessing and Monitoring Livelihoods in Situations of Chronic Conflict and Political Instability. London: Overseas Development Institute.

Kelman, I. 2010. Hearing Local Voices from Small Island Developing States for Climate Change. Local Environment 15 (7): 605-619.

Kelman, I., and J. C. Gaillard. 2010. Embedding Climate Change Adaptation within Disaster Risk Reduction. In Climate Change Adaptation and Disaster Risk Reduction: Issues and Challenges, edited by R. Shaw, J. M. Pulhin, and J. J. Pereira, 23-46. Bedfordshire: Emerald Books.

King, A. 2012. Mauritania Scenario Analysis 2011-12: Five Livelihood Zones Assessed Using the Household Economy Approach (HEA), Food Economy Group (FEG). http://www.hea-sahel.org/documents/ Outcomes-analysis//OUTCA-MR-2011-2012-Report-EN.pdf.

Kirono, D. 2010. Climate Change in Timor Leste - A Brief Overview on Future Climate Projections. Aspendale: CSIRO National Research Flagships.

Larsen, S. C. 2006. The Future's Past: Politics of Time and Territory Among Dakelh First Nations in British Columbia. Geografiska Annaler Series B 88 (3): 311-321.

Louis, R. P. 2007. Can You Hear Us Now? Voices from the Margin: Using Indigenous Methodologies in Geographic Research. Geographical Research 45 (2): 130-139.

Majid, N., and S. McDowell. 2012. Hidden Dimensions of the Somalia Famine. Global Food Security 1 (1): 36-42.

McEntire, D. A. 2004. Development, Disasters and Vulnerability: A Discussion of Divergent Theories and the Need for Their Integration. Disaster Prevention and Management 13 (3): 193-198.

Mercer, J. 2010. Disaster Risk Reduction or Climate Change Adaptation: Are We Reinventing the Wheel? Journal of International Development Policy 22 (2): 247-264.

Mercer, J., I. Kelman, L. Taranis, and S. Suchet-Pearson. 2010. Framework for Integrating Indigenous and Scientific Knowledge for Disaster Risk Reduction. Disasters 34 (1): 214-239.

Mitchell, T. 2003. An Operational Framework for Mainstreaming Disaster Risk Reduction. Benfield Hazard Research Centre Disaster Studies Working Paper 8. http://www.undp.org.cu/crmi/docs/bhrcdrrmainstrfrwk-td-2003-en.pdf.

Molyneux, N., G. Da Cruz, R. Williams, R. Andersen, and N. Turner. 2012. Climate Change and Population Growth in Timor Leste: Implications for Food Security. Ambio 41 (8): 823-840.

Okoth, J. 2011. Karamoja Food Security Seasonal Assessment: 06/11/2011-28/11/2011. FAO Uganda. http://www.disasterriskreduction. net/east-central-africa-old/events/detail/en/c/93824/.

Rethman, C. 2012. SADC Regional Vulnerability Assessment and Analysis Programme. Personal communication in a research meeting, 13 July 2012. 
RTF-URR (Asian Regional Task Force on Urban Risk Reduction ), UNISDR, and Kyoto University. 2010. A Guide for Implementing the Hyogo Framework for Action by Local Stakeholders. http://www. preventionweb.net/files/13101_ImplementingtheHFA.pdf.

Schmuck-Widmann, H. 2001. Facing the Jamuna River: Indigenous and Engineering Knowledge in Bangladesh. Dhaka: Bangladesh Resource Centre for Indigenous Knowledge.

Seaman, J. 2000. Making Exchange Entitlements Operational: The Food Economy Approach to Famine Prediction and the RiskMap Computer Program. Disasters 24 (2): 133-152.

Stephen, L., and T. Downing. 2001. Getting the Scale Right: A Comparison of Analytical Methods for Vulnerability Assessment and Household-level Targeting. Disasters 25 (2): 113-135.

Sundnes, K., and M. Birnbaum. 2003. Health Disaster Management Guidelines for Evaluation and Research in the Utstein Style. Volume 1: Conceptual Framework of Disasters. Prehospital and Disaster Medicine 17 (3): 1-168.

Tran, P., and R. Shaw. 2007. Towards an Integrated Approach of Disaster and Environmental Management: A Case Study of Thua Thien Hue Province in Central Vietnam. Environmental Hazards 7 (4): 271282.

Turner, B. L., R. E. Kasperson, P. A. Matson, J. J. McCarthy, R. W. Corell, L. Christensen, N. Eckley, et al. 2003. A Framework for Vulnerability Analysis in Sustainability Science. Proceedings of the National Academy of Sciences 100 (14): 8074-8079.
Venton, C., C. Fitzgibbon, T. Shitarek, L. Coulter, and O. Dooley. 2012. The Economics of Early Response and Disaster Resilience: Evidence from Kenya and Ethiopia. https://www.gov.uk/government/uploads/ system/uploads/attachment_data/file/67330/Econ-Ear-Rec-ResFull-Report 20.pdf.

WFP/UNHCR (World Food Programme / United Nations High Commissioner for Refugees). 1997. WFP/UNHCR Guidelines for Estimating Food and Nutritional Needs in an Emergency. Geneva: World Food Programme.

White, G. F., R. W. Kates, and I. Burton. 2001. Knowing Better and Losing Even More: The Use of Knowledge in Hazards Management. Global Environmental Change Part B: Environmental Hazards 3 (3-4): 81-92.

Wisner, B., P. Blaikie, T. Cannon, and I. Davis. 2004. At Risk: Natural Hazards, People's Vulnerability, and Disasters, 2nd ed. London: Routledge.

Wisner, B., J. C. Gaillard, and I. Kelman. 2012. Framing Disaster: Theories and Stories Seeking to Understand Hazards, Vulnerability and Risk. In: Handbook of Hazards and Disaster Risk Reduction, edited by B. Wisner, J. C. Gaillard, and I. Kelman, 18-33. Abingdon: Routledge.

World Bank. 2010. Timor Leste: Raising Agricultural Productivity: Issues and Options: A Policy Note. http://rural-development.tl/ library/finish/4-02-technical-documents/28-productivity-technicalnote-1-irrigation-2009/0.

Open Access This article is distributed under the terms of the Creative Commons Attribution License which permits any use, distribution, and reproduction in any medium, provided the original author(s) and source are credited. 